\title{
Microinsemination with First-Wave Round Spermatids from Immature Male Mice
}

\author{
Hiromi MIKI $I^{1,2)}$, Jiyoung LEE ${ }^{3,4)}$, Kimiko INOUE ${ }^{1,4)}$, Narumi OGONUKI'), \\ Yoko NOGUCHI ${ }^{5)}$, Keiji MOCHIDA ${ }^{1}$, Takashi KOHDA ${ }^{4,6)}$, \\ Hiroshi NAGASHIMA ${ }^{2)}$, Fumitoshi ISHINO ${ }^{3,4)}$ and Atsuo OGURA ${ }^{1,4)}$
}

\author{
1) Institute of Physical and Chemical Research (RIKEN), 3-1-1, Koyadai, Tsukuba, Ibaraki 305- \\ 0074, ${ }^{2)}$ Meiji University Graduate School, Kanagawa 214-8571, ${ }^{3)}$ Medical Research Institute, \\ Tokyo Medical and Dental University, 2-3-10 Kandasurugadai, Chiyoda-ku, Tokyo 101- \\ 0062, ${ }^{4}$ CREST, JST, Saitama 332-0012, 5) National Institute of Infectious Diseases, Tokyo 162- \\ $8640,{ }^{6}$ Center for Biological Resources and Informatics, Tokyo Institute of Technology, \\ Kanagawa 226-8501, Japan
}

\begin{abstract}
In several mammalian species, including mice, round spermatids have been used to produce normal offspring by means of microinsemination techniques. In this study, we examined whether mouse round spermatids retrieved from immature testes undergoing the first wave of spermatogenesis had acquired fertilizing ability comparable to cells from mature adults. Microinsemination with round spermatids was performed by direct injection into preactivated oocytes, as previously reported. About $60-85 \%$ of the successfully injected oocytes developed to the morula/blastocyst stage after $72 \mathrm{~h}$ in culture, irrespective of the age of the males (17-25 days old). After embryo transfer, normal pups were obtained from all age groups, including the day-17 group, the stage at which the first round spermatids appeared. A high correlation $(r=0.90)$ was found between the birth rate and male age $(\mathrm{P}<0.01$, Spearman rank correlation), indicating that the efficiency of producing offspring was dependent on the age of the donor males. Imprinted genes (H19, Igf2, $M e g 3$, and Igf2r) were expressed from the correct parental alleles (maternal, paternal, maternal, and maternal, respectively) in all $(\mathrm{n}=12)$ day-9.5 fetuses derived from day-20 spermatids. These results clearly indicate that at least some first-wave spermatogenic cells have a normal haploid genome with the correct paternal imprint and are capable of supporting full-term embryo development, as do mature spermatozoa from adults. The use of male germ cells from immature animals may save time in the production of inbred/congenic strains and rescue male-factor infertility of early onset.
\end{abstract}

Key words: Microinsemination, Spermatogenesis, Spermatid, Genomic imprinting, Mouse

(J. Reprod. Dev. 50: 131-137, 2004)

M icroinsemination, also called intracytoplasmic sperm injection (ICSI), is a technique that is used to deliver spermatozoa directly into oocytes with micromanipulation devices. This technique has provided invaluable information on several biological and molecular aspects of mammalian

Accepted for publication: November 18, 2003

Correspondence: A. Ogura (e-mail: ogura@rtc.riken.go.jp) fertilization that could never be achieved by conventional in vitro fertilization (IVF). With ICSI, it was first demonstrated that sperm-egg membrane fusion can be bypassed for normal fertilization and subsequent embryo development [1-3]. With recent technical advances, immature sperm cells (spermatogenic cells) at certain stages in the testes have also been used to construct 
diploid zygotes (for review, see [4, 5]). Normal offspring have been obtained by using spermatids, the haploid male germ cells produced before the completion of spermiogenesis, in mice [6], rabbits [7], rats [8], mastomys [9], rhesus monkeys [10], and humans [11]. This indicates that the spermatid genome is genetically and epigenetically competent to support full-term development, just like mature spermatozoa.

The microinsemination experiments undertaken to date have used spermatozoa or spermatogenic cells collected from mature testes. In mammals, spermatogenesis starts shortly before puberty, and the first-wave spermatogenic cells undergo meiosis and subsequent spermiogenesis in an environment that is endocrinologically and structurally different from that of the mature testis. Many of them die at the spermatocyte stage because of a phase of increased apoptosis, which is thought necessary for maturation of the seminiferous epithelium [12]. The first-wave spermatogenic cells never participate in fertilization during the normal course of sex maturation, and IVF with these cells is usually very inefficient [13]. Therefore, there is the question of whether male gametes from first-wave spermatogenesis are biologically equivalent to those from adults. In this study, we used the microinsemination technique to examine whether mouse round spermatids retrieved from immature testes have already acquired fertilizing ability comparable to cells from mature testes.

\section{Materials and Methods}

\section{Collection of oocytes}

Mature oocytes were collected from the oviducts of B6D2F1 females (SLC Co., Shizuoka, Japan) that were induced to superovulate with $7.5 \mathrm{IU}$ equine chorionic gonadotropin (eCG) followed $48 \mathrm{~h}$ later with 7.5 IU human chronic gonadotropin (hCG). They were placed in KSOM medium [14] and treated with $0.1 \%$ bovine testicular hyaluronidase until the cumulus cells dispersed. The oocytes were placed in drops of KSOM, covered with mineral oil (Nacalai, Tokyo, Japan), and kept in plastic dishes (Falcon No. 1008, Becton Dickinson, NJ, USA) under $5 \% \mathrm{CO}_{2}$ in air, at $37 \mathrm{C}$ until use.

\section{Collection of spermatogenic cells}

Spermatogenic cells were mechanically isolated from the seminiferous tubules of ICR (Clea Japan, Tokyo, Japan) or JF1 (M. m. molossinus) males at 1625 days of age, as described previously [15]. The cell suspension was washed by centrifugation twice and stored in Dulbecco's phosphate-buffered saline containing $5.6 \mathrm{mM}$ glucose, $5.4 \mathrm{mM}$ sodium lactate, and $0.5 \%$ bovine serum albumin (BSA, fraction $\mathrm{V}$, Calbiochem, CA, USA) [15] at $4 \mathrm{C}$ for up to $4 \mathrm{~h}$.

\section{Microinsemination with round spermatids}

Identification and injection of round spermatids were performed as previously reported [16]. About $60 \mathrm{~min}$ before spermatid injection, oocytes were activated by treatment with $\mathrm{Ca}^{2+}$-free KSOM containing $5 \mathrm{mM} \mathrm{SrCl}_{2}$ for $20 \mathrm{~min}$. The spermatid nucleus, together with a small volume of the cytoplasm, was injected into oocytes advancing to telophase II by using a Piezo-driven micromanipulator. All the procedures were performed at room temperature (24-26 C). The injected oocytes were then kept at room temperature for about 10 minutes before they were incubated at $37 \mathrm{C}$. Oocytes that survived injection were cultured at $37 \mathrm{C}$ under $5 \% \mathrm{CO}_{2}$ in air.

\section{Embryo transfer}

Embryos that reached the morula/blastocyst stage by $72 \mathrm{~h}$ in culture were transferred into pseudopregnant ICR females (8 to 12 weeks old) on day 2.5. Some four- to eight-cell-stage embryos were transferred into the oviducts of day-1 recipient females after $48 \mathrm{~h}$ in culture. On day 19.5, the recipient females were examined for the presence of fetuses, and live pups were nursed by lactating ICR females. Some females were sacrificed at day 9.5 to collect fetuses and placentas for gene expression analysis.

\section{Allele expression analysis of imprinted genes}

To see the paternal imprinting status of spermatids used for microinsemination, we performed an allele expression analysis of imprinted genes in fetuses and placentas generated by an intersubspecies cross, i.e., B6D2F1 oocytes $x$ JF1 spermatids. Polymorphisms of three imprinted genes (H19, Igf2, and Meg3) and one imprinted gene (Igf2r) between B6D2F1 and JF1 were detected by restriction fragment length polymorphism (RFLP) and length polymorphism (LP), respectively. Total RNA extraction from fetal and placental tissues, cDNA synthesis, and RT-PCR with appropriate 
primer sets were performed as described previously [17].

\section{Results}

In vitro development of spermatid-injected oocytes

Round spermatids were identified in the spermatogenic cell suspension retrieved from testes at day 17 and older, but not at day 16 . Conventional histological examination confirmed this finding (Fig. 1). Therefore, we performed microinsemination experiments with round spermatids from day 17-25 males, together with round spermatids from adults as controls. Most (> $90 \%$ ) oocytes treated with $\mathrm{Sr}^{2+}$ reached telophase II with a half-protruding second polar body within 60 min. After they had been injected with round spermatids, about $80-90 \%$ of the oocytes survived and subsequently formed female and male pronuclei. The rates of cleavage and development to the morula/blastocyst stage were consistent throughout the experiments, ranging from 78 to $98 \%$ and 60 to $85 \%$, respectively (Table 1 ).

\section{In vivo development of spermatid-injected oocytes}

After transfer into the oviducts or uteri of recipient females, about $20-35 \%$ of the embryos underwent implantation, irrespective of the age of the males used (Table 1). At term, normal pups were obtained from each age group, including day17 males (Table 1, Fig. 2), the stage at which the first round spermatids appeared. Two pups (females) derived from day-17 ICR spermatids grew into normal adults and were proven fertile by natural mating. The rate of development to term per embryo transfer was very low with younger males. Then we arcsin transformed the birth rates and examined whether there was any correlation with male age. A high correlation $(\mathrm{r}=0.90)$ was found between the birth rate and male age $(\mathrm{P}<0.01$, Spearman rank correlation) (Fig. 3), indicating that the efficiency of producing offspring from firstwave round spermatids was dependent on the age of the donor males.

\section{Allele expression analysis of imprinted genes}

To analyze imprinted gene expression, we performed round spermatid injection with JF1 males at 17, 19, 20, and 21 days of age. Term offspring were obtained from day-20 spermatids, but not from day-17, -19 , or -21 spermatids. We examined the active alleles of three imprinted genes (H19, Igf2, and Meg3) in the term placenta derived from day-20 spermatids. All $(n=4)$ the placentas expressed the correct allele of these three imprinted genes (maternal, paternal and maternal, respectively) (data not shown). Since it was possible that only fetuses with normal imprinted gene expression reached term, we extended our analysis to fetuses at day 9.5, the stage to which some fetuses may survive even with aberrant genomic imprinting, as seen in the development of parthenogenetic or androgenetic fetuses [18]. We
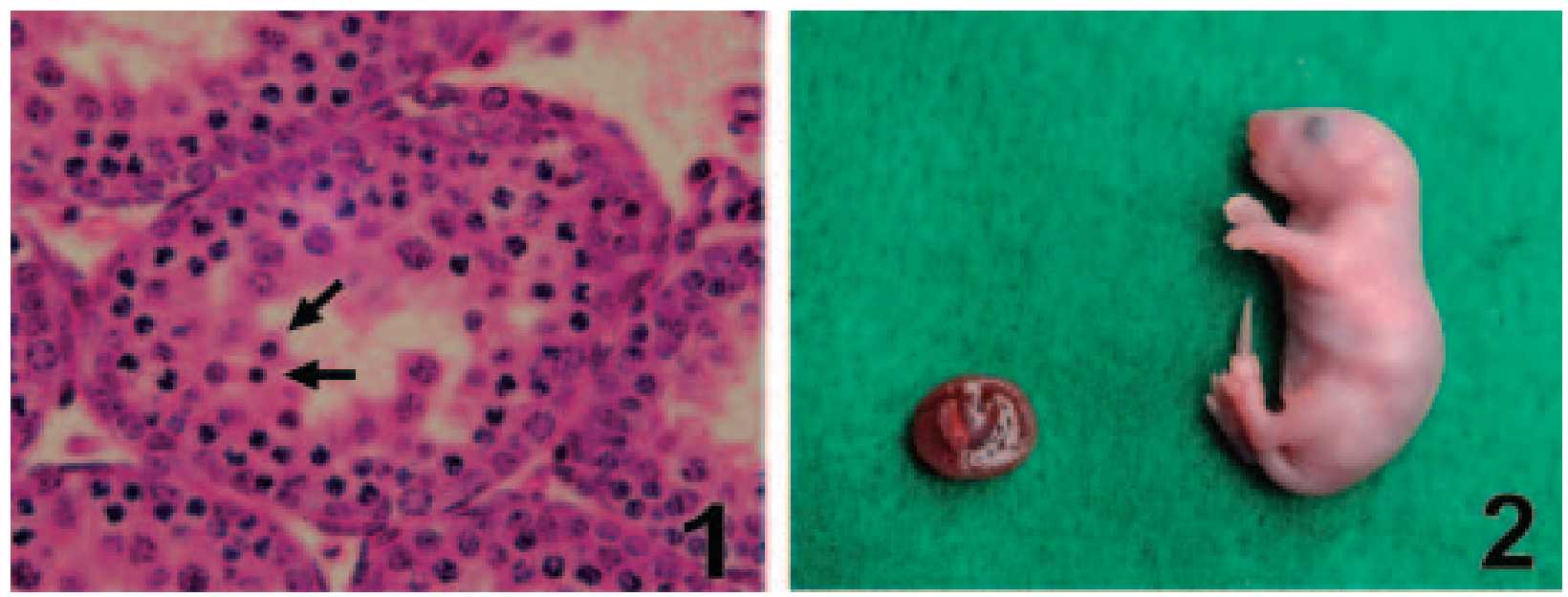

Fig. 1. The seminiferous tubules of a testis at 17 days of age. A few round spermatids that have just completed meiosis are found in some seminiferous tubules (arrows).

Fig. 2. A female pup born following microinsemination with a round spermatid at 17 days of age. It grew into a normal fertile adult. 
Table 1. Embryo development in vitro and in vivo after injection with round spermatid at different ages

\begin{tabular}{|c|c|c|c|c|c|c|c|c|c|c|}
\hline \multirow{2}{*}{$\begin{array}{l}\begin{array}{c}\text { Age of } \\
\text { males } \\
\text { (days)* }^{*}\end{array} \\
\text { Adult }\end{array}$} & \multirow{2}{*}{$\begin{array}{c}\begin{array}{c}\text { No. of } \\
\text { experiment }\end{array} \\
3\end{array}$} & \multicolumn{2}{|c|}{$\begin{array}{l}\text { No. cleaved/ } \\
\text { cultured (\%) }\end{array}$} & \multicolumn{2}{|c|}{$\begin{array}{c}\text { No. } \\
\left(\mathrm{M}+\mathrm{B}^{* *}\right) / \text { cultured } \\
(\%)\end{array}$} & \multirow{2}{*}{$\begin{array}{c}\text { No. } \\
\text { transferred }^{* * *} \\
108\end{array}$} & \multicolumn{2}{|c|}{$\begin{array}{c}\text { No. }(\%) \\
\text { implanted }\end{array}$} & \multicolumn{2}{|c|}{$\begin{array}{c}\text { No. }(\%) \text { of } \\
\text { fetuses }\end{array}$} \\
\hline & & $133 / 143$ & $(93.0)$ & $108 / 143$ & $(75.5)$ & & 34 & $(31.5)$ & 20 & (18.5) \\
\hline 25 & 2 & 109 / 130 & (83.8) & 82 / 130 & $(63.1)$ & 82 & 10 & $(12.2)$ & 12 & (14.6) \\
\hline 24 & 2 & 155 / 159 & (97.5) & $136 / 159$ & $(85.5)$ & 136 & 20 & (14.7) & 18 & (13.2) \\
\hline 23 & 2 & $121 / 128$ & $(94.5)$ & $55 / 67$ & $(82.1)$ & 107 & 37 & $(34.6)$ & 16 & (15.0) \\
\hline 22 & 2 & $131 / 151$ & $(86.8)$ & $125 / 151$ & $(82.8)$ & 125 & 18 & (14.4) & 10 & (8.0) \\
\hline 21 & 4 & 247 / 298 & (82.9) & $126 / 210$ & $(60.0)$ & 201 & 44 & $(22.0)$ & 16 & (8.0) \\
\hline 20 & 2 & $174 / 190$ & (91.6) & $127 / 190$ & $(66.8)$ & 127 & 26 & $(20.4)$ & 13 & (10.2) \\
\hline 19 & 4 & $220 / 239$ & (92.1) & 83 / 117 & (70.9) & 190 & 29 & (16.3) & 15 & (7.9) \\
\hline 18 & 2 & $63 / 81$ & $(77.8)$ & 48 / 81 & $(59.3)$ & 48 & 10 & $(25.0)$ & 2 & $(4.2)$ \\
\hline 17 & 4 & 316 / 359 & $(88.0)$ & $159 / 267$ & $(59.6)$ & 214 & 24 & (19.4) & 2 & $(0.9)$ \\
\hline
\end{tabular}

*Inclusive results from JF1 males at day 17, 19, 20, and 21. Results from ICR males and JF1 males were combined because the timing of the first wave spermatogenesis was the same for these strains.

**Morulae and blastocysts.

***Some of the embryos were transferred at the 4 - to 8 -cell stages after $48 \mathrm{hr}$ in culture.

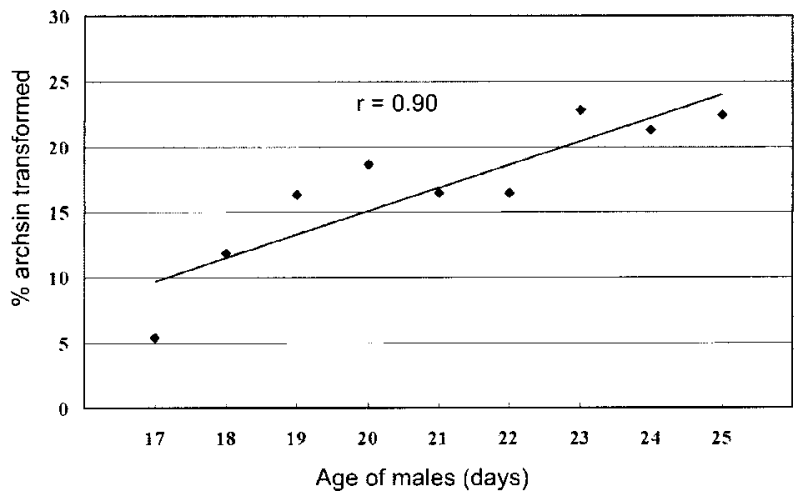

Fig. 3. The birth rates after the transfer of embryos derived from microinsemination with first-wave spermatids of different ages. The values after arcsin transformation are shown. There is a high correlation between the birth rate and the age of the donor males $(r=0.90$, Spearman rank correlation).

examined twelve fetuses, including those with developmental retardation, and found that four imprinted genes (H19, Igf2, Meg3 and Igf2r) were correctly expressed from each parental allele in all of the fetuses examined (Table 2, Fig. 4).

\section{Discussion}

This study examined whether the ability of firstwave spermatogenic cells to fertilize oocytes and to support embryo development is comparable to that of cells from mature testes. After injection with first-wave round spermatids, some oocytes were successfully fertilized and subsequently developed into normal term offspring. Even with day-17 spermatids, the first haploid gametes to appear in newborn male mice, we obtained two normal pups that grew into fertile adults. These findings clearly indicate that at least some first-wave spermatogenic cells have a fully functional genome, despite the difference in the testicular environments of prepubertal and adult animals. But efficiency, as measured by embryos that developed to term, was low when the youngest spermatids were used. It is important to determine whether this has a biological or technical cause.

If the younger round spermatids have a normal chromosomal constitution, as do older round spermatids, their poor developmental competency might be due to epigenetic factors. Fetal development is significantly affected by parentspecific epigenetic memory (genomic imprinting) [19]. This parent-specific memory is marked for certain genes (imprinted genes) during gametogenesis. A previous microinsemination study revealed that round spermatids from adult testes had a genomic imprinting status similar to that of mature spermatozoa [20]. The exact stage at which paternal imprinting is completed is unknown, but analysis of the DNA methylation pattern of differentially methylated regions (DMRs) of a paternally imprinted (methylated) gene, H19, suggested that paternal genomic imprinting occurs in primordial germ cells from day 15.5 or 16.5 of pregnancy [21, 22]. Therefore, it 
Table 2. Allelic analysis of $9.5 \mathrm{dpc}$ fetuses obtaind from 20 day-old JF1 males

\begin{tabular}{ccccccccccccc}
\hline & Fetus 1 & 2 & 3 & 4 & 5 & 6 & 7 & 8 & $9^{*}$ & $10^{*}$ & 11 & 12 \\
\hline H19 & $\mathrm{M}$ & $\mathrm{M}$ & $\mathrm{M}$ & $\mathrm{M} *$ & $\mathrm{M}$ & $\mathrm{M}$ & $\mathrm{M}$ & $\mathrm{M}$ & $\mathrm{M}$ & $\mathrm{M}$ & $\mathrm{M}$ & $\mathrm{M}$ \\
Igf2 & $\mathrm{P}$ & $\mathrm{P}$ & $\mathrm{P}$ & $\mathrm{P}$ & $\mathrm{P}$ & $\mathrm{P}$ & $\mathrm{P}$ & $\mathrm{P}$ & $\mathrm{P}$ & $\mathrm{P}$ & $\mathrm{P}$ & $\mathrm{P}$ \\
Meg3 & $\mathrm{M}$ & $\mathrm{M}$ & $\mathrm{M}$ & $\mathrm{M}$ & $\mathrm{M}$ & $\mathrm{M}$ & $\mathrm{M}$ & $\mathrm{M}$ & $\mathrm{M}$ & $\mathrm{M}$ & $\mathrm{M}$ & $\mathrm{M}$ \\
$\operatorname{Igf2r}$ & $\mathrm{M}$ & $\mathrm{M}$ & $\mathrm{M}$ & $\mathrm{M}$ & $\mathrm{M}$ & $\mathrm{M}$ & $\mathrm{M}$ & $\mathrm{M}$ & $\mathrm{M}$ & $\mathrm{M}$ & $\mathrm{M}$ & $\mathrm{M}$ \\
\hline
\end{tabular}

M: maternal expression, P: paternal expression.

*Smaller than normal (about $50 \%$ of normal weight).

**With a small level (about 10\%) of expression from the paternal allele.

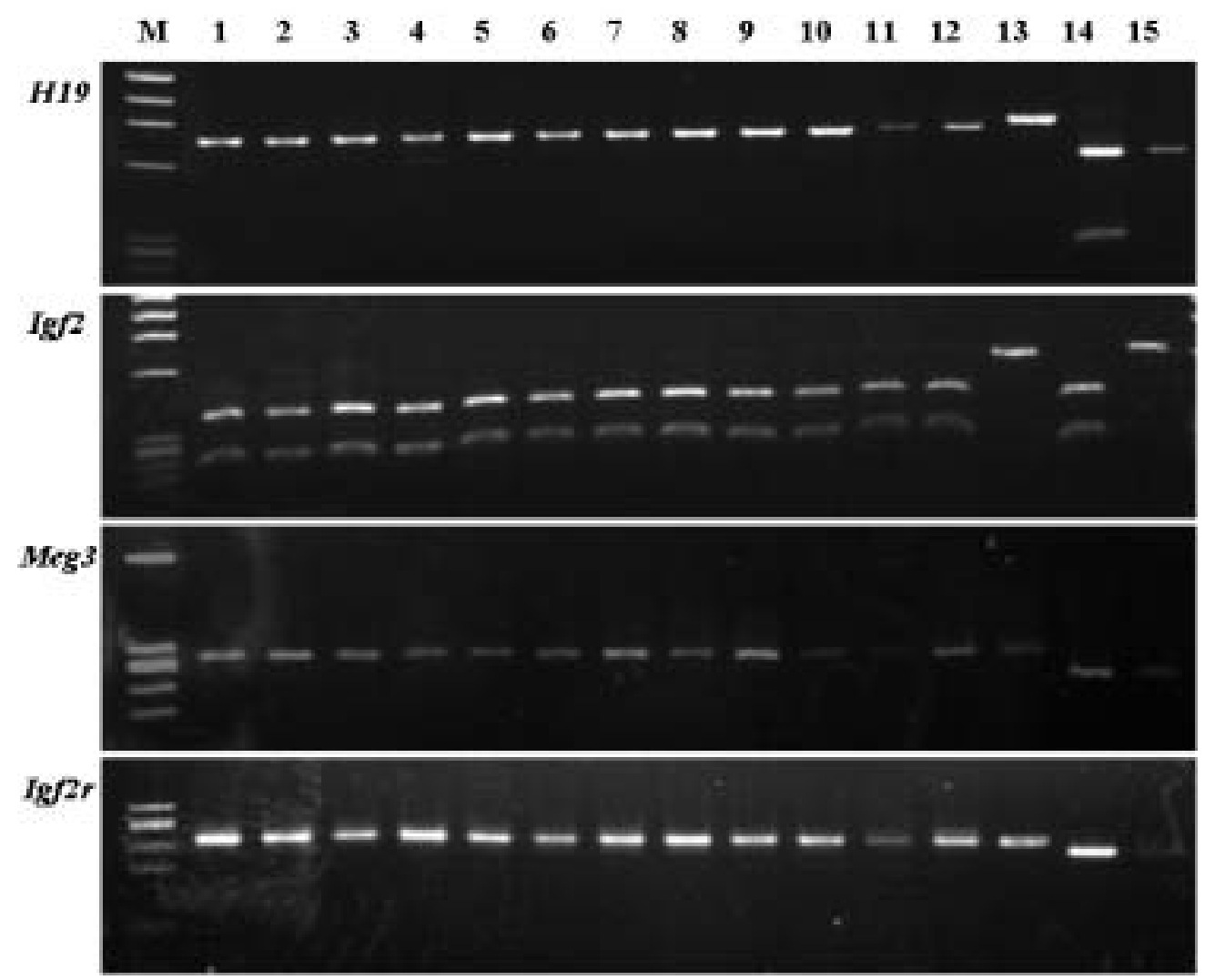

Fig. 4. Expression analysis of the H19, Igf2, Meg3 and $\operatorname{Igf} 2 r$ genes in day-9.5 fetuses derived from injection with day-20 JF1 spermatids. These genes are correctly expressed from the maternal (BDF1), paternal (JF1), maternal, and maternal allele, respectively. M: marker, Lanes 1-12: BDF1 $\times$ JF1 day-9.5 fetuses from spermatid injection (cDNA), Lane 13: B6D2F1 genomic DNA, Line 14: JF1 genomic DNA, Lane 15: control JF1 $\times$ B6 day 9.5-fetus (cDNA).

is very probable that paternal imprinting memory has been completed in first-wave round spermatids, which appear about three weeks after the initiation of the paternal imprint. Our allele expression analysis of paternally imprinted genes (H19, Igf2, and Meg3) supported this assumption, because all the day-9.5 fetuses derived from day-20 spermatids expressed the correct alleles (maternal, paternal, and maternal, respectively). A maternally imprinted gene (Igf2r) was also expressed correctly. Therefore, it is unlikely that incomplete genomic imprinting affects the postimplantation development of embryos derived from first-wave round spermatids.

The population of round spermatids was relatively small in younger testes, as compared 
with that of older testes. Therefore, when these younger males were used as donors, small cells other than round spermatids would be more likely to be identified erroneously and injected into oocytes. When we selected presumptive round spermatids from cell suspensions at day 17 and from adults, the accuracy as determined by the haploid chromosomal constitution within MII oocytes was $63 \%(12 / 19)$ and $89 \%(33 / 37)$, respectively (unpublished data). In our supplemental experiments, oocytes injected with cumulus cells instead of spermatids developed into morulae/blastocysts at a rate comparable to that of spermatid-derived embryos. After transfer, these $3 n$ embryos induced the implantation reaction (decidualization), although the embryo proper, if any, was developmentally retarded (unpublished). This developmental pattern is similar to that found in this study, because embryos from younger males showed poor development to term, but showed normal development until implantation. Therefore, it is probable that technical factors, such as erroneous cell identification, are involved, at least to some extent, in the poor in vivo development of embryos derived from younger first-wave round spermatids.

Our results have a practical implication in mouse genetics. One of the general purposes of microinsemination techniques is the production of offspring from infertile males that cannot be rescued with conventional IVF [4]. Recently, the number of mouse strains has been increasing due to the production of new transgenic/knockout mouse strains. These genetically engineered mice may carry expected or unexpected disorders that lead to spermatogenesis failure. The use of male germ cells from immature males may rescue early-onset malefactor sterility due to spermatogenic arrest from idiopathic causes or secondary to a poor systemic condition. Furthermore, the fact that healthy fertile offspring can be obtained by microinsemination with spermatids from prepubertal males indicates that generation turnover can be accelerated during inbreeding or serial back crossing. In the mouse, each generation takes at least 3 months. With conventional superovulation, oocytes can be collected from prepubertal females at 25-30 days of age [23]. If these precociously ovulated oocytes can be fertilized with first-wave spermatids, the generation time can be shortened to $45-50$ days (adding a 20-day gestation), about half of the normal generation time. To make such a technique more practical, we need to understand the biological and physical nature of oocytes and spermatogenic cells from different inbred strains, which will be an integral part of future microinsemination studies in the mouse.

\section{Acknowledgments}

This work was supported by grants from MEXT, MHLW, CREST, and the Human Science Foundation, Japan.

\section{References}

1. Hosoi Y, Miyake M, Utsumi K, Iritani A. Development of rabbit oocytes after microinjection of spermatozoa. Proceedings of the 11th International Congress on Animal Reproduction 1988; 3: abs.331.

2. Goto K, Kinoshita A, Takuma Y, Ogawa K. Fertilisation of bovine oocytes by the injection of immobilized, killed spermatozoa. Vet Rec 1990; 127: 517-520.

3. Palermo G, Joris H, Debroey P, Van Steirteghem AC. Pregnancies after intracytoplasmic injection of single spermatozoon into an oocyte. Lancet 1992; 340: 17-18.

4. Ogura A, Ogonuki N, Takano K, Inoue $\mathrm{K}$. Microinsemination, nuclear transfer, and cytoplasmic transfer: the application of new reproductive engineering techniques to mouse genetics. Mamm Genome 2001; 12: 803-812.

5. Ogura A, Ogonuki N, Inoue K. Microinsemination and nuclear transfer with male germ cells. In: Cibelli JB, Lanza R, Campbell K, West MD (eds.), Principles of Cloning. San Diego: Academic Press; 2002: 175186.

6. Ogura A, Matsuda J, Yanagimachi R. Birth of normal young following fertilization of mouse oocytes with round spermatids by electrofusion. Proc Natl Acad Sci USA 1994; 91: 7460-7462.

7. Sofikitis NV, Miyagawa I, Agapitos E, Pasyianos P, Toda T, Hellstrom WJG, Kawamura $H$. Reproductive capacity of the nucleus of the male gamete after completion of meiosis. J Assist Reprod Genet 1994; 11: 335-341. 
8. Hirabayashi M, Kato M, Aoto T, Ueda M, Hochi S. Rescue of infertile transgenic rat lines by intracytoplasmic injection of cryopreserved round spermatids. Mol Reprod Dev 2002; 62: 295-299.

9. Ogonuki N, Mochida K, Inoue $K$, Matsuda J, Yamamoto Y, Takano K, Ogura A. Fertilization of oocytes and birth of normal pups following intracytoplasmic injection with spermatids in mastomys (Praomys coucha). Biol Reprod 2003; 68: 1821-1827.

10. Hewitson L, Martinovich C, Simerly C, Takahashi D, Schatten G. Rhesus offspring produced by intracytoplasmic injection of testicular sperm and elongated spermatids. Fertil Steril 2002; 77: 794-801.

11. Tesarik J, Mendoza C, Testart J. Viable embryos from injection of round spermatids into oocytes. New Eng J Med 1995; 333: 525.

12. Billig H, Furuta I, Rivier C, Tapanainen J, Parvinen M, Hsueh A. Apoptosis in testis germ cells: developmental changes in gonadotropin dependence and localization to selective tubular stages. Endocrinology 1995; 136: 5-12.

13. Bleil JD. In vitro fertilization. In: Wassarman PM, DePamphilis ML (eds.), Guide to Techniques in Mouse Development. San Diego: Academic Press; 1993: 253-263

14. Lawitts JA, Biggers JD. Culture of preimplantation embryos. Methods Enzymol 1993; 225: 153-164.

15. Ogura A, Yanagimachi R. Round spermatid nuclei injected into hamster oocytes form pronuclei and participate in syngamy. Biol Reprod 1993; 48: 219225.

16. Kimura Y, Yanagimachi R. Mouse oocytes injected with testicular spermatozoa or round spermatids can develop into normal offspring. Development
1995; 121: 2397-2405.

17. Lee J, Inoue $\mathbf{K}$, Ono R, Ogonuki N, Kohda K, Kaneko-Ishino T, Ogura A, Ishino F. Erasing genomic imprinting memory in mouse clone embryos produced from day 11.5 primordial germ cells. Development 2002; 129: 1807-1817.

18. McGrath J, Solter D. Completion of mouse embryogenesis requires both the maternal and paternal genomes. Cell 1984; 37: 179-83.

19. Reik W, Walter J. Genomic imprinting: Parental influence on the genome. Nat Rev Genet 2001; 2: 2132.

20. Shamanski FL, Kimura Y, Lavoir M-C, Pedersen RA, Yanagimachi R. Status of genomic imprinting in mouse spermatids. Hum Reprod 1999; 14: 10501056.

21. Ueda T, Abe K, Miura A, Yuzuriha M, Zubair M, Noguchi M, Niwa K, Kawase Y, Kono T, Matsuda Y, Fujimoto H, Shibata H, Hayashizaki Y, Sasaki $\mathbf{H}$. The paternal methylation imprint of the mouse $\mathrm{H} 19$ locus is acquired in the gonocyte stage during foetal testis development. Genes Cells 2000; 5: 649659.

22. Yamazaki Y, Mann MRW, Lee SS, Marh J, McCarrey JR, Yanagimachi R, Bartolomei MS. Reprogramming of primordial germ cells begins before migration into the genital redge, making these cells inadequate donors for reproductive cloning. Proc Natl Acad Sci USA 2003; 100: 1220712212.

23. Nagy A, Gertsenstein M, Vintersten $K$, Behringer R. Inducing superovulation. In: Manipulating the Mouse Embryo. 3rd ed, New York: Cold Springer Harbor Laboratory Press; 2003: 148-150. 